\title{
Alışveriş Maliyetleri Parasal Hizmet Modeli: Türkiye Örneği ${ }^{*}$
}

\author{
Ahmet Çetin ${ }^{\mathrm{a}}$
}

\section{Özet}

Bu çalışmada, Ratti ve Jeong (1994)'ın Alışveriş Maliyetleri Parasal Hizmet Modeli, 1989:01-1999:12 dönemlerini kapsayan Türkiye'nin aylık verilerine uygulanmıştır. Veri setinde yapısal kırılma tespit edildiğinden eşbütünleşme ve hata düzeltme modelleri, yapısal kırılma dikkate alınarak uygulanmıştır. Elde edilen ampirik bulgulara göre, Türkiye'de reel döviz kurunun para ikamesinin kaynaklarından biri olduğu yönünde deliller ortaya konmuştur.

Anahtar Kelimeler: Para ikamesi; eşbütünleşme; yapısal kırılma; reel döviz kuru belirsizliği

\begin{abstract}
In this study, Shopping Costs version of Money Services Model constructed by Ratti and Jeong (1994) was applied to Turkish monthly data for the period of 1989:011999:12. Since structural break is founded in the data, cointegration analysis and error correction model are employed in the light of structural break. According to the empirical finding, it is founded that one of the sources of currency substitution is reel exchange rate uncertainty in Turkey.
\end{abstract}

Keywords: Currency substitution; cointegration; structural break; real exchange rate uncertainty

\footnotetext{
* Bu çalışmaya değerli katkılar sağlayan Prof. Dr. Kuter ATAÇ’a, Prof. Dr. Orham MORGíl'e, Prof. Dr.Tuba ONGUN'a, Prof. Dr. Erdinç TELATAR'a, Doç. Dr. Merhal ÖZHAN'a ve Yrd. Doç. Dr. Naci CANPOLATA çok teşekkür ederiz. Çalışmadaki olası hata ve eksikliklerin sorumluluğu yalnızca yazarlara aittir.

a Yrd. Doç.Dr. Gaziosmanpaşa Üniversitesi, İ̈BF, Tokat, akcetin@gop.edu.tr
} 


\section{Giriş}

Para ikamesinin ilk orijinal çalışmaları Kouri (1976) ve Calvo ve Rodriquez (1977) tarafından göreceli olarak yakın tarihlerde yapılmış olmasına rağmen, bu konudaki çalışmalar çok hızlı bir gelişim göstermiştir. Son yirmi yılda para ikamesi konusunda tatminkar sayıda teorik ve ampirik çalışma yapılmasına rağmen yaygın kabul görmüş bir tanımı bulunmamaktadır. Tanımlamalar genel olarak yabancı paranın yerli parayı hangi işlevleriyle ikame ettiğine göre sınıflandırılmaktadır. Dar para ikamesi tanımında yabancı para sadece değişim aracı olarak talep edilmektedir (Cuddington 1989; Calvo ve Vegh 1992). Geniş para ikamesi tanımında ise yabancı para, paranın üç işlevi (değişim aracı olma, değer saklama ve hesap birimi olma) için talep edilir. McKinnon (1985) para ikamesini doğrudan para ikamesi (yabancı paranın değişim aracı olarak talep edilmesi) ve dolaylı para ikamesi (para dişı finansal varlıklar arasındaki ikame) olmak üzere ikiye ayırmıştır. Bazı yazarlar tarafından para ikamesi ve dolarizasyon kavramları eşanlamlı olarak kullanılmaktadır. Diğer bir grup ise hesap birimi olma ve değer saklama işleviyle para talep edilmesine dolarizasyon (Calvo ve Vegh, 1992), değişim aracı olarak yabanc1 para talep edilmesini ise para ikamesi olarak yorumlamaktadır. Diğer bir grup ise para ikamesini yerli para talebinin yabanc1 ekonomik değişkenler tarafından etkilendiği bir süreç olarak tanımlamaktadır (Handa ve Bana, 1990; Rogers 1990; Thomas 1985).

Para ikamesi modelleri genel olarak "portföy dengesi modelleri" (Cuddington, 1983; Branson ve Henderson, 1985; Zervoyianni 1988, 1992) ve "parasal hizmet modelleri” (Miles, 1978; Jonies, 1985; Bergstrand ve Bundt, 1990) olmak üzere ikiye ayrılırlar. Bu iki model arasındaki temel farklılık para talep fonksiyonunu farklı tanımlamalarından kaynaklanmaktadır.

Portföy dengesi modelinde ihtiyat nedeniyle para talebine önem verilmekte ve para mali varlık gibi değerlendirilmektedir. Mali servet, tüm mali varlıklar arasından taşıdıkları risk ve göreli beklenen getiriye göre belirlenmektedir. Portföyde yerli ve yabancı paraların taşıdıkları risk ve beklenen getiri oranındaki değişme sonucu yerli paradan yabancı paraya doğru kayma para ikamesi olarak yorumlanmaktadır.

Parasal hizmet modelinde ise iki aşamalı bir süreç söz konusudur. İlk aşamada mali servet, paralar (yerli ve yabancı) ve diğer mali varlıklar (yerli ve 
yabancı bonolar) olmak üzere ikiye ayrılır. İkinci aşamada ise hem paraların hem de bonoların ne kadarının yerli ve ne kadarının yabancı olacağına karar verilir. Servetin hangi oranda para olarak tutulacağına birinci aşamada karar verildiğinden yabancı faiz oranının göreli olarak yükselmesi yabancı parayı elde tutma göreli maliyetini artıracak ve birey yabancı parayı yerli parayla ikame etme yoluna girecektir.

Parasal hizmet modeli iki yönüyle eleştirilere maruz kalmıştır. Birincisi, iki aşamalı portföy oluşturma süreci gerçekçi bir kısıtlama değildir. Her bir dönemde mali varlık mevcutken bireyler kendilerini iki aşamalı olarak sınırlandırmazlar. İkincisi ise, yabancı para talebinde dış ticaret kaynaklı bir faktör bulunmamaktadır. Oysa, ithalat ihtiyacı için de yabancı paraya ihtiyaç duyulmaktadır. Ratti ve Jeong (1994) parasal hizmet modelini geliştirerek bu iki eksikliği ortadan kaldırmıştır. Geliştirilen modelde bireysel tüketim ve para talebi dönemlerarası (intertemporal) bir yapıya kavuşturularak bireye istediği zaman para ile bono arasında değişiklik yapma imkanı tanınmıştır.

Bu çalışmada Ratti ve Jeong (1994)'ın geliştirmiş olduklar "Alışveriş Maliyetleri Parasal Hizmet Modeli” kullanılarak Türkiye'deki para ikamesi olgusu açıklanmaya çalışılacaktır.

\section{Alışveriş Maliyetleri Parasal Hizmet Modeli}

Ratti ve Jeong (1994) modelinde, parasal hizmet modeline alışveriş maliyetini eklenmiş ve dönemlerarası dinamik optimizasyon çözümlemesine giderilmiştir. Modeldeki temel varsayım, paranın sağlamış olduğu hizmetten dolayı talep edilmesidir. Modelde, sonsuz zaman dilimde ekonomik karar birimi, parasal hizmet kaynakları kısıtlaması altında, faydasını maksimize etmeye çalışmaktadır. Tüketim için yerli ve yabancı para kullanılmaktadır. Değişim için gerekli reel kaynakların bir kısmı V fonksiyonu tarafından temsil edilmektedir.

$$
\mathrm{V}=\mathrm{V}\left(\mathrm{m}^{*} ; \theta\right), \quad \mathrm{V}_{\mathrm{m}^{*}}<0,
$$

Denklem (1)'de m* parasal hizmet düzeyini ve $\theta$, değişim için ihtiyaç duyulan kaynaklardaki parasal hizmet düzeyini etkileyen teknolojik ve kurumsal faktörleri temsil etmektedir. Denklem (1)'de değişim için gerekli reel 
kaynak düzeyi ile parasal hizmet düzeyi arasında ters yönlü bir ilişki kurulmaktadır. Parasal hizmet düzeyi ise denklem (2)'de tanımlanmıştır.

$$
\mathrm{m}^{*}=\mathrm{m} *\left(\frac{M_{d}}{P_{d}}, \frac{M_{f}}{P_{f}}, \phi\right), \quad \mathrm{m}_{1}, \mathrm{~m}_{2}>0
$$

Denklem (2)'de parasal hizmet düzeyi yerli ve yabacı para düzeyine bağlı olarak verilmiştir. Denklem (2)'de; $\mathrm{M}_{\mathrm{d}}$ ve $\mathrm{M}_{\mathrm{f}}$ sırasıyla nominal yerli ve yabancı para düzeyini; $\mathrm{P}_{\mathrm{d}}$ ve $\mathrm{P}_{\mathrm{f}}$, sırasıyla yerli ve yabancı fiyatlar genel düzeyini ifade etmektedir. Denklem (2)'deki $\phi$ göreceli para tercihini etkileyen diğer faktörleri (uluslararası ticaretin genişlemesi gibi) temsil etmektedir.

Her bir dönemdeki toplam reel mali varlıklar denklem (3)'de verilmiştir.

$$
\mathrm{a}=\frac{M_{d}}{P_{d}}+\frac{S \cdot M_{f}}{P_{d}}+\frac{B_{d}}{P_{d}}+\frac{S \cdot B_{f}}{P_{d}},
$$

Denklem (3)'de $B_{d}$ ve $B_{f}$ sirasiyla, yerli ve yabacı para cinsinden yerli ve yabancı bonoları göstermektedir. $\mathrm{S}$ ise spot döviz kurunu ifade etmektedir. Denklem (3)'de tüm mali varlıklar yerli para türünden ifade edilmiştir.

Mali varlık birikimini bulmak için gelirden tüketim çıkartılır ve mali varlıklardaki net getiri eklenir. Varlık birikimi, denklem (4)'de verilmiştir.

$$
\begin{aligned}
\dot{a}= & y-c\left[1+V\left(m *\left(\frac{M_{d}}{P_{d}}, \frac{M_{f}}{P_{f}}, \phi\right) ; \theta\right)\right]-\pi_{d}\left(\frac{M_{d}}{P_{d}}\right)+\left(\varepsilon-\pi_{d}\right) \frac{S \cdot M_{f}}{P_{d}} \\
& +\left(r_{d}-\pi_{d}\right) \frac{B_{d}}{P_{d}}+\left[\varepsilon\left(1+r_{f}\right)+r_{f}-\pi_{d}\right] \frac{S \cdot B_{f}}{P_{d}}
\end{aligned}
$$

Denklem (4)'deki “ $\dot{a}$ ”, a değişkeninin zamana göre türevinin alındığını göstermektedir. Denklem (4)'de beklenen döviz kuru değişim oranı " $\varepsilon$ " olarak tanımlanmıştır. Denklem (4)'deki değişkenler; $\varepsilon=(\mathrm{dS} / \mathrm{dt}) / \mathrm{S}$, döviz kurunda beklenen değişim oranını; $\pi_{d}$, yerli ülke enflasyon oranını; $r_{d}$ ve $r_{f}$, sırasıyla yerli ve yabancı bonolardaki faiz oranını; $y$, reel gelirini ve c, reel tüketimi ifade etmektedir. 
Denklem (4)'deki bileşenlerden, ilk bileşen, geliri; ikinci bileşen, tüketimi; üçüncü bileşen, nakit olarak tutulan yerli paradaki enflasyon aşınmasını; dördüncü bileşen, nakit olarak tutulan yabancı paradaki döviz kuru/enflasyon etkilerinden sonraki net getiriyi; beşinci bileşen, yerli bonodaki faiz geliri ve enflasyon aşınmasından sonraki net getiriyi ve altıncı bileşen, yabancı bonodaki döviz kuru, faiz geliri ve enflasyon aşınmasından sonraki net getiriyi ifade etmektedir.

Fayda fonksiyonu denklem (5)'de verilmiştir. Denklem (5)'de $\delta$ zaman iskonto oranını vermektedir.

$$
U=\int_{0}^{\infty} u\left(c_{t}\right) e^{-\delta t} d t, \quad u^{\prime}>0, \quad u^{\prime \prime}<0
$$

Fayda fonksiyonu denklem (3)'deki stok mali kaynaklarının ve denklem (4)'deki akım mali kaynaklarının kısıtlaması altında çözüldüğünde denklem (6)'ya ulaşılır.

$$
\frac{m_{1}^{*}\left(\frac{M_{d}}{P_{d}}, \frac{M_{f}}{P_{f}}, \phi\right)}{m_{2}^{*}\left(\frac{M_{d}}{P_{d}}, \frac{M_{f}}{P_{f}}, \phi\right)}=\left(\frac{S \cdot P_{f}}{P_{d}}\right)\left(\frac{r_{d}}{r_{f}(1+\varepsilon)}\right)
$$

Denklem (6)'da elde edilen ilişkide, yerli para ile yabancı para arasındaki marjinal ikame oranı, reel döviz kuruna ve yerli para tutmanın firsat maliyetinin yabancı para tutmanın fırsat maliyetine oranına bağlı olduğu görülmektedir. Elde edilen bu ilişki, uygulamada kullanılabilecek bir forma dönüştürülürken parasal hizmet modelinin Sabit İkame Esnekliği (CES) denklem formu sahip olduğu varsayılır ve para ikamesini etkileyen $\phi$ değişkenini temsilen dış ticaret hadleri (E/I) kullanılır. Elde edilen denkleme logaritmik dönüşüm uygulandığında nihai denklem formuna ulaşılmış olur. 
$\log \left(\frac{M_{d}}{S \cdot M_{f}}\right)_{t}=\gamma_{0}+\gamma_{1} \log \left[\left(\frac{r_{f}}{r_{d}}\right)(1+\varepsilon)\right]_{t}+\gamma_{2} \log \left(S \frac{P_{f}}{P_{d}}\right)_{t}+\gamma_{3} \log \left(\frac{E}{I}\right)_{t}+\mu_{t}(7)$

Denklem (7)'de, sol taraftaki değişken yerli paranın yabancı paraya oranını göstermektedir. $\gamma_{1}$ katsayısı bono yerine para tutmanın göreli firsat maliyetini göstermekte ve $\gamma_{1}>0$ olarak beklenmektedir. $\gamma_{2}$ göreli para talebinde reel döviz kurundaki değişmenin etkisini göstermekte ve $\gamma_{2}<0$ olarak beklenmektedir. Denklem (7)'deki üçüncü değişken olan $\log (\mathrm{E} / \mathrm{I})$, modelden çıkan bir sonuç değildir. Modelde para tercihlerini etkileyen diğer faktörler Ratti ve Jeong (1994) tarafından ihracatın (E) ithalata (I) oranı olarak tercih edilmiştir. Üçüncü değişken ihracatın ithalata oranı olduğundan $\gamma_{3}$ katsayısının beklenen değeri pozitiftir.

\section{Materyal ve Yöntem}

\subsection{Materyal}

Modelden elde edilen ilişkilerin Türkiye verilerine uygulanabilmesi için, bazı düzenlemelerin yapılması gerekmektedir. Düzenleme ihtiyacı duyulan ilk konu, yabancı para olgusudur. Türkiye'de yabanc1 para olarak tek bir para birimi değil, iki para birimi çok yaygın olarak kullanılmaktadır. Bu para birimleri, ABD doları ve Alman markıdır. ${ }^{1}$ Bu nedenle yabancı ülke olarak tek bir ülke değil, ABD ve Almanya'dan oluşan temsili bir yabancı ülke kullanılacaktır. Türkiye'deki yabancı para miktarlarını takip edebilmek için dolar ve marktan oluşan bir efektif döviz kuru oluşturulmuştur. Efektif döviz kurunda, ağırlık oranı yüzde 75 dolar ve yüzde 25 mark olarak belirlenmiştir. ${ }^{2}$ Efektif döviz kuru için seçilen ağırlık oranları yabacı ülke değişkeni olan,

\footnotetext{
1 Alman mark1 Ocak 2002'de tedavülden kalkmıș ve euro tedavüle sürülmüştür; ama araştırmanın kapsadığı 1989-1999 yılları arasında Alman markı Türkiye'de çok tercih edilen yabancı paralardan birisi olmuştur. Araştırma dönemi içinde euro fiilen piyasada bulunmamaktadır.

${ }_{2}^{2}$ Ağırlıklandırma hatasından kaçınmak için, doların $0.00, \quad 0.25, \quad 0.50, \quad 0.75$ ve 1.00 ağırlıklandırma oranları kullanılmış ve bu ağırlıklandırma sonuçlarında doların 0.75 ağırlıklı olduğu efektif döviz kurunun en iyi ağırlık oranı olduğu tespit edilmiştir.
} 
yabanc1 bono faiz oranı ve yabanc1 ülke fiyat endeksinde de aynı oranlarda kullanılmıştır.

Düzenleme ihtiyacı duyulan ikinci konu ise döviz kurunda beklenen değişim oranıdır. Ratti ve Jeong (1994) yaptıkları çalışmada, döviz kurunda beklenen değişim oranı $(\varepsilon)$, vadeli döviz piyasası ile spot döviz piyasası arasındaki fark olarak temsil edilmiştir. Oysa, Türkiye'de vadeli döviz piyasası bulunmamaktadır. Bu nedenle, döviz kuru oranında beklenen değişim oranı döviz kurundaki oynaklık ile temsil edilmiş ve döviz kurundaki oynaklık Genelleştirilmiş Otoregresif Koşullu Değişen Varyans (GARCH) modeli ile tahmin edilmiştir.

\subsection{Veriler}

Kullanılan orijinal veriler iki temel kaynaktan alınmıştır. Bunlar, Türkiye Cumhuriyet Merkez Bankası (TCMB) ve Uluslararası Finansal İstatistikler (IFS) dır. Bunlar dışında herhangi bir kuruluş tarafından üretilmeyen ve eksik olan bazı veriler çeşitli hesaplama ve tahmin metotları ile elde edilmiştir. Araştırma dönemi Ocak 1989 - Aralık 1999 dönemlerini kapsamaktadır. Veriler; aylık ${ }^{3}$, sabit ve dönem sonu değerleri olarak alınmışlardır. Kullanılan serilerin temel özellikleri Ek (1)'de açıklanmıştır.

$\mathrm{Bu}$ çalışmanın uygulama dönemi seçilirken bazı kriterler sınırlayıcı etki yapmışlardır. Türkiye'de yabancı mevduata izin verilen ilk yıllarda düzenli veriye ulaşılamamıştır. ${ }^{4}$ Daha sonraki birkaç yıl ise, araştırma dönemi dışında tutularak veri seti başlangıç etkilerinden korunmaya çalışılmışıı. Uygulama döneminin bitiş tarihi ise başlıca iki faktörün sınırlaması altında belirlenmiştir. Bunlardan birincisi, Türkiye'nin 1999 sonunda IMF ile yaptığı stand-by ${ }^{5}$ anlaşmasıdır. IMF İcra Kurulu'nun 22 Aralık 1999 tarihinde stand-by anlaşmasını onaylamasıyla, Türkiye ile IMF arasında üç yıllık stand-by programı başlamıştır. Programla birlikte döviz kurlarını çıpaya bağlanmıştır.

\footnotetext{
${ }^{3}$ Uygulama üç-aylık serilerle de yapılmış ama üç-aylık serilerle yapılan uygulamalarda alınan sonuçlarla aylık veriler kullanılarak elde edilen sonuçlara çok yakın olduğundan üç-aylık verilerle elde edilen sonuçların raporlanmasına ihtiyaç duyulmamıştır.

${ }^{4} 29$ Aralı 1983 tarihinde çıkarılan 28 sayılı kararname ve 30 Temmuz 1984 tarihli 30 sayılı kararname ile yerleşiklere döviz tevdiat hesabı açabilme izni verilmiştir. 1989 yılı Ağustos ayında Bakanlar Kurulu Kararı ile kambiyo kontrolleri kaldırılarak yurtdışı sermaye hareketleri serbest bırakılmıştır.

${ }^{5}$ Türkiye'nin IMF ile yapmış olduğu stand-by anlaşmaları için bkz http://www.hazine.gov.tr
} 
İkinci kısıtlama ise, efektif döviz kurunu oluşturan iki yabancı paradan biri olan Alman markının, Avrupa Birliği'nin euroya geçmesiyle Ocak 2002'de tedavülden kalkmasıdır. Alman markının tedavülden kalktığı tarihe kadar uygulama sürdürülememiştir. Bunun nedeni, IMF stand-by anlaşmasının veri seti üzerinde bozucu etkilere sahip olmasıdır. Bu nedenlerden dolay1, IMF stand-by anlaşması belirleyici bir unsur olmuş ve stand-by anlaşmasının başlangıç tarihi araştırma dönemi bitiş tarihi olarak belirlenmiştir. Belirtilen bu nedenlerden dolayı, araştırma dönemi 1989:01-1999:12 olarak belirlenmiştir.

\subsection{Beklenen Döviz Kuru Oranının Tahmini: GARCH Modeli}

Döviz kurunun otoregresif bir süreç içerdiği varsayımıyla GARCH modeli genel olarak aşağıdaki gibi modellenebilir. ${ }^{6}$

$$
\begin{aligned}
& S_{t}=a_{0}+a_{1} S_{t-1}+u_{t} \\
& u_{t} \mid \Omega_{t-1} \sim\left(0, h_{t}\right) \\
& h_{t}=\alpha_{0}+\sum_{i=1}^{q} \alpha_{i} u_{t-i}^{2}+\sum_{i=1}^{p} \beta_{i} h_{t-i}
\end{aligned}
$$

Denklemlerde kullanılan S, spot döviz kurunu; u, hata terimi; $\Omega$, bilgi setini; ve h, koşullu varyans ifade etmektedir. Denklem (8)'de nominal döviz kuru otoregresif bir süreç olarak tanımlanmıştır. Bu serinin herhangi bir zamandaki varyansını hesaplayabilmek için GARCH modeli kullanılmıştır. GARCH modelinde hata teriminin koşullu varyansı $h_{t}$ hem kendi gecikmesine (lag değerlerine) hem de hata teriminin karesine $\left(\mathrm{u}^{2}\right)$ bağlı tanımlanmaktadır. Denklem (9)'da hata teriminin koşullu beklenen değeri sıfır, varyansının ise değişken olduğu $\left(\mathrm{h}_{\mathrm{t}}\right)$ belirtilmektedir. Denklem (10)'da ise değişen varyans tanımlanmaktadır.

Daha önce tanımlanan efektif döviz kuru serisindeki beklenen değişim oranı GARCH $(1,1)$ modeli ile tahmin edilmiş ve tahmin sonuçları Tablo (1)'de verilmiştir.

\footnotetext{
${ }^{6}$ Türkiye'de döviz kuru belirsizliğinin modellenmesi için Bkz. Telatar (1996) ve Telatar (2003).
} 
A. Çetin / Sosyal Bilimler Araştırmaları Dergisi , 1, (2006): 15-39

Tablo 1. Efektif Döviz Kuru Serisinden Döviz Kuru Değişim Oranının Tahmin Sonuçları

\begin{tabular}{l|cccc}
\hline \multicolumn{1}{c|}{ Değişken } & Tahmin & Standart Hata & t-Değeri & $\operatorname{Pr}>|\mathrm{t}|$ \\
\hline Sabit & 6.1169 & 0.0378 & 162.03 & $<.0001$ \\
Trend & 0.0423 & 0.000297 & 142.51 & $<.0001$ \\
AR1 & -0.9669 & 0.002162 & -447.30 & $<.0001$ \\
ARCH1 & 0.2783 & 0.023908 & 11.64 & $<.0001$ \\
GARCH1 & 0.7217 & 0.023905 & 30.19 & $<.0001$ \\
\hline
\end{tabular}

Tablo (1)'de görüldüğü gibi GARCH modelinin tüm parametreleri \%1 anlamlılık düzeyinde istatistiksel olarak anlamlıdır. GARCH1 $(\beta)$ parametresi döviz kuru değişim serisindeki oynaklığın süreklilik (persistence) derecesini ölçmektedir. Katsayının 1'e yakın olması bir şok gerçekleştiğinde oynaklığın uzun bir süre etkili olacağını ifade etmektedir. ARCH1 $(\alpha)$ parametresi otoregresif koşullu varyansı ölçmektedir. GARCH1 $(0,7217)$ değerinin ARCH1 $(0,2783)$ değerinden yüksek olması, şokun uzun dönem etkilerinin kısa dönem etkilerinden daha güçlü olduğunun göstermektedir. AR1 parametresi birinci derece otokorelasyon katsayısını göstermektedir. Sabit $\left(\mathrm{a}_{0}\right)$ parametresi sabit terimi ifade etmektedir.

\subsection{Birim Kök Testleri ve Yapısal Kırılma}

$\mathrm{Bu}$ çalışmada, kullanılacak değişkenler Genişletilmiş Dickey-Fuller ${ }^{7}$ (ADF) ve Phillips-Parron ${ }^{8}$ (PP) birim kök testlerine tabi tutulmuşlardır. Test sonuçları Tablo(2)'de verilmiştir.

\footnotetext{
${ }^{7}$ Detaylı bilgi için Bkz. Dickey ve Fuller $(1979,1981)$

${ }^{8}$ PP birim kök testi Phillips ve Perron (1988) tarafından, hata teriminin dağılımı hakkındaki varsayımların gevşetilerek DF testinin geniş̧letilmesiyle geliştirilmiştir.
} 
Tablo 2. Değișkenlerin ADF ve PP Birim Kök Test Sonuçları ${ }^{9}$

\begin{tabular}{|l|ccc|c|}
\hline \multirow{2}{*}{ Değişkenler } & \multicolumn{2}{|c|}{ Genişletilmiş Dickey-Fuller } & \multicolumn{2}{c|}{ Phillips-Parron } \\
\cline { 2 - 5 } & Düzey & Birinci Fark & Düzey & Birinci Fark \\
\hline $\log (\mathrm{M} 2 / \mathrm{DTH})$ & -1.82 & $-10.26^{* *}$ & -1.82 & $-10.23^{* *}$ \\
\hline $\log \left[\left(\mathrm{r}_{\mathrm{f}} / \mathrm{r}_{\mathrm{d}}\right)(1+\varepsilon)\right]$ & -1.68 & $-10.33^{* *}$ & -1.72 & $-10.33^{* *}$ \\
\hline $\log \left[\mathrm{S} .\left(\mathrm{P}_{\mathrm{f}} / \mathrm{P}_{\mathrm{d}}\right)\right]$ & -2.31 & $-10.03^{* *}$ & -2.53 & $-10.03^{* *}$ \\
\hline $\log (\mathrm{E} / \mathrm{I})$ & $-3.76^{* *}$ & -- & $-5.49^{* *}$ & -- \\
\hline
\end{tabular}

** \%1 Önem seviyesinde $\mathrm{H}_{0}$ hipotezini (birim kök varllğını) reddetmektedir.

Tablo (2)'de görüldüğü gibi, dış ticaret $(\mathrm{E} / \mathrm{I})$ değişkeni dışındaki tüm değiş̧kenler birim kök içermektedirler. Başka bir ifadeyle, dış ticaret hadleri durağan, diğer serileri ise durağan değildir. Durağan olmayan serilerin birinci farkları alındığında tüm seriler durağan hale gelmektedir. Birim kök testinde kullanılan iki farklı test olan ADF ve PP testleri birbirleriye paralel sonuçlar vermişlerdir. Dış ticaret değişkeni durağan çıktığından eşbütünleşme analizine dahil edilmeyecektir. ${ }^{10}$

Yapısal kırılma konuda yapılan çeşitli çalışmalarda, kullanılan zaman serilerinde bir kırılma varsa ve bu kırılma dikkate alınmadan birim kök testi uygulanırsa, serilerin durağan çıkmama yönünde güçlü bir eğilimi olduğu görülmüştür (Ben-David ve Papell, 1994). Oysa kırılma dikkate alındığında, durağan çıkmayan birçok seri durağan özellikler göstermektedir. Birim kök testlerinden daha gerçekçi sonuçlar elde etmek için serideki kırılmaları da dikkate alan birim kök testleri geliştirilmiştir. Geliştirilen testlerden birisi de Zivot ve Andrews (1992) tarafından yapılmıştır. Testin uygulanmasında karşılaşılan sorunların başında kırılma noktasının hangi dönemde gerçekleştiği sorunudur. Kırılma noktası, araştırmacı tarafından dışsal olarak belirlenebilir ve bu noktada kırılma olup olmadığı test edilebilir. Ama araştırmacı kullandığı seride kırılmanın varlığı hakkında bilgi sahibi olmayabilir. Bu durumda, kırılmanın varlığının test edilmesi ve varsa kırılma noktasının tespit edilmesi gerekmektedir.

\footnotetext{
${ }^{9}$ ADF birim kök testinin uygulanmasında gecikme uzunluğunun seçiminde Schwartz Bilgi Ölçütü (SIC) kullanılmıştır. PP birim kök testinde ise Bartlett Kernel ve Newey-West Bandwidth yöntemleri kullanılmıştır.

${ }^{10}$ Eşbütünleşme analizi için serilerin durağan olmaması gerekmektedir. Bu nedenle bu değişken eşbütünleşme analizine dahil edilememektedir. Bu durum ilerde daha detaylı açıklanmıştır.
} 
Zivot ve Andrews (1992) modifikasyona tabi tuttukları ADF birim kök testinde kırılma noktasını içsel bir süreçte belirlemektedirler. Zivot-Andrews (ZA) ardış1k birim kök testi (sequential unit root test) üç ayrı modelden oluşmaktadır. Üç modelinde $\mathrm{H}_{0}$ hipotezi denklem (11)'de verildiği gibidir.

$$
\mathrm{y}_{\mathrm{t}}=\mu+\mathrm{y}_{\mathrm{t}-1}+\mathrm{e}_{\mathrm{t}}
$$

Denklemde $\mathrm{H}_{0}$ hipotezde $\mathrm{y}_{\mathrm{t}}$ serisinin (dışsal bir kırılma olmadan) birim kök içerdiğini, alternatif hipotezde ise $\mathrm{y}_{\mathrm{t}}$ serisinin bilinmeyen bir noktada bir kırılma ile trend-durağan bir seri oluşturduğudur. ZA sürecinin amacı ardışık olarak her bir noktayı kırılma noktası olarak test etmek ve alternatifler arasında en uygun trend-durağan noktayı elde etmektir.

ZA modelinde üç farklı ADF regresyonu tanımlanmıştır. A Modelinde, bilinmeyen bir dönemde kırılmanın sabit terimde olduğunu varsaymaktadır. A Modelinde En Küçük Kareler (EKK) yöntemi ile tahmin edilmesi gereken regresyon denklem (12)'de verildiği gibidir.

$$
\Delta \mathrm{y}_{\mathrm{t}}=\mu+\theta \mathrm{DU}_{\mathrm{t}}+\beta \mathrm{t}+\alpha \mathrm{y}_{\mathrm{t}-1}+\sum_{j=1}^{k} c_{j} \Delta y_{t-j}+\mathrm{e}_{\mathrm{t}}
$$

DU, sabit terimde kırılmayı ifade eden kukla değişkenidir. Trend değişkenini $t$ ifade etmektedir. Kırılmanın olduğu dönem $T_{B}$ olsun. $B u$ durumumda kukla değişkeninin alacağı değerler: eğer $\mathrm{t}>\mathrm{T}_{\mathrm{B}}$ ise $\mathrm{DU}_{\mathrm{t}}=1$, aksi taktirde sıfırdır. A modeli $\mathrm{T}$ gözlem sayısı için $\mathrm{T}_{\mathrm{B}}=2, \ldots, \mathrm{T}-1$ değerleri için tek tek ardışı olarak tahmin edilir. En yüksek $t_{\alpha}$ değerinin olduğu dönem kırılma dönemi olarak alınır. Regresyonda gecikme uzunluğu, "k", seçilirken BenDavid ve Pappell (1994)'in yöntemi tercih edilmiştir. Bu yönteme göre önceden tesadüfi seçilen bir üst " $k$ " değerinden başlanır ve en son gecikme değeri anlamlı bulunana kadar gecikme uzunluğu azaltılarak devam ettirilir. Hiçbir gecikme uzunluğunda anlamlılık yakalanamamışsa sıfır gecikme kullanılır. ZA çalışmasında üst gecikme uzunluğunu $\mathrm{k}=8$ olarak belirlemişlerdir. Kırılma noktası tespit edilen seri A modelindeki regresyon doğrultusunda teste tabi tutulur. Daha öncede belirtildiği gibi $\mathrm{H}_{0}$ hipotez serinin birim kök içerdiğini, alternatif hipotez ise serinin kırılmayla birlikte durağan olduğunu ifade etmektedir. 
B Modelinde, bilinmeyen bir kırılma noktasında kırılmanın eğim katsayısında olduğunu varsaymaktadır. B Modelinde EKK yöntemi ile tahmin edilmesi gereken regresyon denklem (13)'de verildiği gibidir.

$$
\Delta \mathrm{y}_{\mathrm{t}}=\mu+\beta \mathrm{t}+\gamma \mathrm{DT}_{\mathrm{t}}+\alpha \mathrm{y}_{\mathrm{t}-1}+\sum_{j=1}^{k} c_{j} \Delta y_{t-j}+\mathrm{e}_{\mathrm{t}}
$$

DT, eğimdeki kırılmayı ifade eden kukla değişkenidir. Bu durumumda kukla değişkeninin alacağı değerler eğer $t>T_{B}$ ise $D_{t}=1$, aksi taktirde sıfırdır. ${ }^{11}$ Regresyonun test edilmesi ve kırılma noktasının bulunması için A Modelindeki sürecin aynısı tekrarlanır.

C Modelinde, bilinmeyen bir kırılma noktasında kırılmanın hem sabit terimde hem de eğim katsayısında olduğunu varsaymaktadır. C Modelinde EKK yöntemi ile tahmin edilmesi gereken regresyon denklem (14)'de verildiği gibidir.

$$
\Delta \mathrm{y}_{\mathrm{t}}=\mu+\theta \mathrm{DU}_{\mathrm{t}}+\beta \mathrm{t}+\gamma \mathrm{DT}_{\mathrm{t}}+\alpha \mathrm{y}_{\mathrm{t}-1}+\sum_{j=1}^{k} c_{j} \Delta y_{t-j}+\mathrm{e}_{\mathrm{t}}
$$

DT ve DU daha önce açıklandığı gibidir. Regresyonun test edilmesi ve kırılma noktasının bulunması için A ve B modellerindeki süreçlerin aynısı tekrarlanır.

$\mathrm{Bu}$ çalışmada, model seçimi yapılırken önce $\mathrm{C}$ Modelinden başlanmıştır. C Modelinde DU ve DT kukla değişkenlerinin her ikiside t-istatistiğine göre anlamlı çıkmışsa, diğer modeller tahmin edilmemiş ve $\mathrm{C}$ modeli seçilmiştir. DU ve DT değişkenlerinden herhangi birinin t-istatistik değeri anlamsız çıkmışsa, anlamsız çıkan değişken dışlanarak anlamlı değişkeni içeren model tahmin edilmiştir. Bu yöntemle belirlenen uygun modellere ZA ardış1k birim kök testi uygulanmış ve sonuçlar Tablo(3)'de gösterilmiştir.

\footnotetext{
11 Zivot-Andrews $\mathrm{DT}_{\mathrm{t}}=\mathrm{t}-\mathrm{T}_{\mathrm{B}}$ olarak tanımlamıştır. Ben-David ve Papell ise $\mathrm{DT}_{\mathrm{t}}=\mathrm{t}$ olarak tanımlamıştır. $\mathrm{Bu}$ durum Dickey-Fuller test istatistiği açısından bir fark yaratmamaktadır. $\mathrm{Bu}$ çalışmada $\mathrm{DT}_{\mathrm{t}}=\mathrm{t}$ tercih edilmiştir.
} 
A. Çetin / Sosyal Bilimler Araştırmaları Dergisi , 1, (2006): 15-39

Tablo 3. Zivot-Andrews Ardıșık Birim Kök Testi Sonuçları

\begin{tabular}{|c|c|c|c|}
\hline & $\log (\mathrm{M} 2 / \mathrm{DTH})$ & $\log \left[\left(\mathrm{r}_{\mathrm{f}} / \mathrm{r}_{\mathrm{d}}\right)(1+\varepsilon)\right]$ & $\log \left[\mathrm{S} .\left(\mathrm{P}_{\mathrm{f}} / \mathrm{P}_{\mathrm{d}}\right)\right]$ \\
\hline Kır1lma & 1994:05 & 1994:06 & 1993:12 \\
\hline $\mathrm{k}$ & 8 & 0 & 3 \\
\hline$\mu$ & $\begin{array}{l}0.220 \\
(3.92)\end{array}$ & $\begin{array}{c}-0.12 \\
(-3.12)\end{array}$ & $\begin{array}{c}0.76 \\
(5.27)\end{array}$ \\
\hline$\theta$ & $\begin{array}{c}-0.19 \\
(-3.41)\end{array}$ & $\begin{array}{c}-0.09 \\
(-2.23)\end{array}$ & $\begin{array}{c}0.03 \\
(4.67)\end{array}$ \\
\hline$\beta$ & $\begin{array}{l}-0.003 \\
(-4.54)\end{array}$ & $\begin{array}{l}-0.002 \\
(-3.64)\end{array}$ & $\begin{array}{c}-0.0003 \\
(-3.84)\end{array}$ \\
\hline$\gamma$ & $\begin{array}{l}0.003 \\
(4.30)\end{array}$ & $\begin{array}{c}0.002 \\
(-2.23)\end{array}$ & ---- \\
\hline$\alpha$ & $\begin{array}{c}-0.25 \\
(-3.94)\end{array}$ & $\begin{array}{c}-0.19 \\
(-3.46)\end{array}$ & $\begin{array}{c}-0.27 \\
(-5.27)\end{array}$ \\
\hline t-istatistik & 3.94 & -3.46 & 5.27 \\
\hline MODEL & $\mathrm{C}$ & $\mathrm{C}$ & A \\
\hline
\end{tabular}

ZA ardışık birim kök testinden elde edilen sonuçlar kırılmayı dikkate almadan yapılan birim kök testleri ile karşılaştırıldığında tek bir değişkenin durumunda değişiklik olduğu tespit edilmiştir. Reel döviz kuru \%5 önem seviyesinde durağan çıkarken \%1 önem seviyesinde halen durağan değildir. Kırılma durumunda da tüm değişkenler \%1 önem seviyesinde durağan değildir.

\subsection{Eşbütünleşme Analizi ve Yapısal Kırılma}

Zaman serileri içeren regresyonların durağan olmamaları durumunda, serilerdeki ortak trendden dolayı gerçek dışı ilişkiler ortaya koyarak düzmece regresyon problemine yol açar. Düzmece regresyondan kaçınmak için, serilerin ya durağan olması ya da durağan hale getirilmesi gerekmektedir. Durağan olmayan serilerin farkları alınarak durağan hale getirilmesi, serilerin birbirleriyle olan uzun dönem ilişkilerinin yok olmasına neden olur. Düzmece regresyondan kaçınmak için yapılan bu işlem, aynı zamanda çok değerli bilgiler içeren uzun dönem ilişkinin de kaybolmasına neden olmaktadır. 
Eşbütünleşme analizi, aralarında uzun dönem ilişkisi olan değişkenlerin, bu uzun dönem bilgilerini kaybetmeden ilişkiyi incelemeye çalışır. Durağan olmayan ancak aynı dereceden entegre serilerin doğrusal birleşimleri durağan ise bu seriler eşbütünleşik serilerdir (Enders, 1995). İki farklı eşbütünleşme test metodu bulunmaktadır. Bunlar, Engel-Granger (1987) ve Johansen-Julelius (1990) yöntemleridir. İkiden fazla değişken olması durumunda, birden fazla eşbütünleşme ilişkisini ihmal eden Engel-Granger metodu etkili sonuç verememektedir. Bu çalışmada, ikiden fazla değişken bulunduğundan JohansenJulelius metodu uygulanmıştır. Metot, " $n$ " tane birinci dereceden entegre serinin otoregresif vektör (VAR) modeline dayanmaktadır. Birinci farkların hata düzeltme (EC) formu, denklem (15)'de verildiği gibidir.

$\Delta \mathrm{W}_{\mathrm{t}}=\mathrm{A}_{1} \Delta \mathrm{W}_{\mathrm{t}-1}+\mathrm{A}_{2} \Delta \mathrm{W}_{\mathrm{t}-2}+\ldots+\mathrm{A}_{\mathrm{p}-1} \Delta \mathrm{W}_{\mathrm{t}-\mathrm{p}+1}+\Pi \mathrm{W}_{\mathrm{t}-\mathrm{p}}+\mu+\mathrm{U}_{\mathrm{t}}$

Denklem (16)'de $\mathrm{W}_{\mathrm{t}}, 3 \times 1$ birinci derece entegre vektör, $\Delta \mathrm{W}_{\mathrm{t}} \equiv \mathrm{W}_{\mathrm{t}}-\mathrm{W}_{\mathrm{t}-1}$, $\mu 3 \times 1$ sabit terim vektörü, П $3 \times 3$ katsayı matriksini ve $U_{t} \sim N(0, \Sigma)$ ifade etmektedir. $\Sigma$, hata teriminin kovaryans matriksidir. Denklem (15)'de $\Delta \mathrm{W}_{\mathrm{t}} \mathrm{I}(0)$ olduğundan sağ tarafin durağan olması ancak $\Pi \mathrm{W}_{\mathrm{t}-\mathrm{p}}$ durağan olması ile gerçekleşebilir.

Tablo (3)'den hatırlanacağı gibi ZA ardışık birim kök testine tabi tutulan tüm değişkenler \%1 önem seviyesinde durağan değildir. Dördüncü değişken olan ticaret hadleri ise durağan çıkmıştır. Eşbütünleşme analizi için serilerin durağan olmaması gerektiği için durağan çıkan ticaret haddi değişkeni analiz dışında tutulacaktır. ${ }^{12}$

Kullanılan veri setindeki seriler yapısal kırılma içermesi, eşbütünleşme denkleminde de yapısal bir kırılma olabileceği şüphesi yaratmaktadır. Uygulama dönemi içinde yapısal değişimin olması modelin istikrarını ortadan kaldırabilir. Eğer model istikrarsız ise tahmin edilen parametreler dönemler arasında farklılık gösterecektir. Yapısal değişimin test edilmesinde en yaygın kullanılan test Chow (1960) testidir. Eğer kırılma noktası k biliniyorsa Chow testi uygulanabilir. Chow testinde $\mathrm{H}_{0}$ hipotezi yapısal kırılmanın olmadı̆̆ını,

\footnotetext{
${ }^{12}$ Ratti ve Jeong (1994)'nun bu modeli Milner, Mizen ve Pentecost (1996) tarafindan Avrupa'da yedi ülkeyi kapsayan bir çalışmada uygulanmıştır. Yapılan çalışmada Almanya'nın dış ticaret hadleri de durağan çıkmış ve bu değişken model dışında tutularak eşbütünleşme analizi yapılmıştır.
} 
alternatif $\mathrm{H}_{1}$ hipotezi ise $\mathrm{k}$ döneminde bir yapısal kırılma olduğunu ifade etmektedir. Burdaki kritik durum, kırılma döneminin bilinip bilinmediğidir. Bu uygulama çalışmasında kırılma noktası hakkında güçlü bilgiler bulunmamaktadır. Andrews (1993), k kırılma noktasının bilinmediği durumlarda, Chow testine kullanılabilir bir fonksiyon kazandırmıştır. Andrews (1993), her bir dönemi olası bir kırılma noktası olarak test etmiş ve her bir dönem için F-testini hesaplamıştır. Her bir gözlem değerine karşılık gelen bir Ftest serisi elde edilmiştir. Eğer modelde bir yapısal kırılma varsa, bu kırılma Ftest değerinin en büyük olduğu dönemde olacaktır. Bu şekilde elde edilen test istatistiğine SupF denmektedir. SupF testinin asimtotik kritik değerleri Andrews (1993) tarafından hesaplanmıştır. ${ }^{13}$ SupF test istatistiğinde kullanılan formül denklem (16)' da verildiği gibidir.

$$
\text { SupF }=\max _{1 \leq t \leq T-1} F_{t}
$$

Denklem (16)'da " $F_{\mathrm{t}}$ ", $\mathrm{t}$ kırılma döneminde hesaplanmış standart $\mathrm{F}$ istatistiğidir. Eğer bu istatistik kritik değerden büyükse kırılmanın olmadığı yönündeki $\mathrm{H}_{0}$ hipotez reddedilir.

$\mathrm{Bu}$ çalışmada, veri setinin test dışında tutulacak başlangış ve sonundan yüzdelik kısmı $\% 5\left(\pi_{0}=5\right)$ olarak alınmıştır. Modelin sağ tarafındaki değişken sayıs1 ise ikidir ( $\mathrm{p}=2$ ). Andrews (1993)'un testindeki kritik değerler \%1, \%5 ve \%10 için sırasıyla, 8.22, 6.48 ve 5.60 değerleridir. Elde edilen SupF (maksimun F-test) değerleri 145.88 bulunmuştur. Modelde kırılma noktasının 1993:02 olduğu tespit edilmiştir. SupF değerlerinin kritik değerlerden çok yüksek olmasından dolayı kırılmanın olmadığ $\mathrm{H}_{0}$ hipotez reddedilir. Andrews testi sonucunda modelde 1993:02 döneminde yapısal kırılma olduğu ve bu kırılmanın modeli istikrarsız yaptığı ortaya konulmuştur.

Eşbütünleşme analizinin yapılacağı dönemde yapısal kırılmanın olması parametrelerin dönemler arasında farklılaşmasına neden olabilir. ${ }^{14} \mathrm{Bu}$ nedenden dolayı kırılmayı dikkate almadan yapılacak eşbütünleşme analizi güvenilmez

\footnotetext{
13 Andrews'un tablosundaki parametrelerden biri olan "p" modeldeki sabit terim dahil sağ taraftaki değişken sayısını ifade etmektedir. Tabloda kritik değerler $\% 10, \% 5$ ve $\% 1$ için hesaplanmıştır. Tablodaki $\pi$ o parametresi, veri setinin başlangıç ve sonundan yüzde kaçın test dişında tutulduğunu ifade etmektedir.

${ }^{14}$ Eşbütünleşme ve rejim değişikliği ilişkisi hakkında daha detaylı bilgi için Bkz Gregory ve Hansen (1996).
} 
sonuçlar ortaya koyacaktır. Bu nedenle, inceleme dönemi ve kırılma öncesi ve kırılma sonrası olmak üzere ikiye ayrılmıştır. Eşbütünleşme analizi önce kırılmayı dikkate almadan tüm dönem için uygulanmış, daha sonra hem kırılma öncesi için, hem de kırılma sonrası için analiz tekrarlanmıştır. Daha önce tam dönem için yapılan birim kök testleri bu sefer kırılma öncesi ve sonrası oluşan dönemler için de tekrarlanmıştır. Kırılma dönemleri için yapılan birim kök test sonuçları Tablo (4)'de verilmiştir.

Tablo (4)'de de görüldüğü gibi, kırılma öncesi değişkenlerin düzey değerlerinin durağan olmadığı; ama birinci farklarının durağan olduğu test sonuçlarından elde edilmiştir. Kırılma sonrasında ise, M2/DTH değişkenlerinin $\% 5$ önem seviyesinde durağan; ama \% 1 anlamlılk düzeyinde durağan olmadıkları tespit edilmiştir. Önem seviyesi \% 1 olarak alındığında, tüm değişkenlerin düzey değerleri durağan değil ama birinci farkları durağandır.

Tablo 4. Yapısal Kırılma Öncesi ve Sonrasında Birim Kök Test Sonuçları

\begin{tabular}{|c|c|c|c|c|c|}
\hline \multirow{2}{*}{\multicolumn{3}{|c|}{ Kırılma Dönemi: 1993:02 }} & \multicolumn{3}{|c|}{ Değişkenler ${ }^{(a)}$} \\
\hline & & & \multirow{2}{*}{$\frac{\mathrm{M} 2 / \mathrm{DTH}}{-2.70}$} & \multirow{2}{*}{$\frac{\left(\mathrm{r}_{\mathrm{f}} / \mathrm{r}_{\mathrm{d}}\right)(1+\varepsilon)}{-2.64}$} & \multirow{2}{*}{$\frac{\mathrm{S} .\left(\mathrm{P}_{\mathrm{f}} / \mathrm{P}_{\mathrm{d}}\right)}{-2.32}$} \\
\hline Kırılma & ADF Birim & Düzey & & & \\
\hline Oncesi & Kök Testi & Birinci Fark & $-6.95 * *$ & $-6.09 * *$ & $-4.17 * *$ \\
\hline \multirow{2}{*}{$\begin{array}{l}\text { Kurılma } \\
\text { Sonras1 }\end{array}$} & \multirow{2}{*}{$\begin{array}{l}\text { ADF Birim } \\
\text { Kök Testi }\end{array}$} & Düzey & $-3.31 *$ & -2.33 & -2.23 \\
\hline & & Birinci Fark & $-8.37 * *$ & $-8.24 * *$ & $-8.51 * *$ \\
\hline
\end{tabular}

Not: * ve ${ }^{* *}$, sirasıyla, $\% 5$ ve $\% 1$ önem seviyesinde $\mathrm{H}_{0}$ hipotezini (birim kök varlığını) reddetmektedir.

(a) Değişkenler logaritmik değerleri ile alınmıştır.

Birim kök testlerinden sonra kırılmanın eşbütünleşme ilişkisi üzerindeki etkileri incelenebilir. Tablo (5)'de, yapısal kırılma durumunda eşbütünleşme ilişkisinin varlı̆̆ 1 , değişkenlerin beklenen işaretlere sahip olup olmadığ irdelemiştir. Modelde tam dönemde ve kırılma öncesinde eşbütünleşme ilişkisi korunurken kırılma sonrası ilişki yok olmuştur. Başka bir ifadeyle, yapısal kırılma sadece kırılma sonrasında eşbütünleşme ilişkisini ortadan kaldırmıştır. 
Tablo 5. Yapısal Kırılma Durumunda Eşbütünleşme Analizi

\begin{tabular}{|c|c|c|c|}
\hline \multirow{2}{*}{ Dönemler } & $\begin{array}{c}\text { Eşbütünleşme } \\
\text { İlişkisi }\end{array}$ & \multicolumn{2}{|c|}{ Değişkenin İşareti ${ }^{(\mathrm{a})}$} \\
\cline { 3 - 4 } & Var & Beklenen İşaretin Tersi & Beklenen İşaret \\
\hline Tam Dönem & Vä $\left(\mathrm{P}_{\mathrm{f}} / \mathrm{P}_{\mathrm{d}}\right)$ \\
\hline Kırılma Öncesi & Var & Beklenen İşaretin Tersi & Beklenen İşaret \\
\hline Kırılma Sonras1 & Yok & ---- & ---- \\
\hline
\end{tabular}

(a) Değişkenler logaritmik değerlerde alınmıştır.

(b) İstatistiksel olarak anlamsız çıkmaktadır.

Tablo (5)'de, kırılmanın eşbütünleşme ilişkisi üzerindeki etkisi dışında değişkenlerin beklenen işaretleri üzerindeki etkileri de gösterilmektedir. Tabloda dikkat çeken en önemli unsur, bu çalışmada öne çıkarılan reel döviz kuru değişkeninin eşbütünleşme ilişkisi olan dönemlerde beklenen işarete sahip olmasıdır. Diğer taraftan faiz değişkeni beklenen işareti verememiştir. ${ }^{15}$ Yapısal kırılma, kırılma sonrası dönemde eşbütünleşme ilişkisinin yok olmasına neden olmuş ve bu dönemin modelle uyumsuz olduğunu ortaya koymuştur.

Tablo (6) modelin Johansen-Juselius eşbütünleşme metodunun sonuçlarını vermektedir. İ ${ }^{16}$ testin $\mathrm{H}_{0}$ hipotezi, sıfır eşbütünleşme ilişkisi (r=0) iken alternatif hipotez bir veya daha fazla eşbütünleşme ilişkisi $(r \geq 1)$ olduğudur. İz testinde $\mathrm{H}_{0}$ hipotez sifir iken, genel alternatif hipotez $\mathrm{r}=1,2,3, \ldots$ dir. Test, sıfır hipotez reddedilmeyene kadar devam ettirilir. Maksimum özdeğer testinin $\mathrm{H}_{0}$ hipotezi de iz testi gibi, eşbütünleşme ilişkisinin olmadığını gösterirken, alternatif hipotez de bir tane ilişki olduğunu ifade etmektedir. Modelde kırılma dikkate alınmadığında tam dönemde sadece iz testinin \%5 önem seviyesinde eşbütünleşme ilişkisini ortaya koyabilmektedir. Maksimum özdeğer testi, bu ilişkiyi desteklememektedir. Kırılma dikkate alındığında kırılma öncesi \%5 anlamlılık düzeyinde hem iz hem de maksimum özdeğer testi eşbütünleşme ilişkisini ortay koymaktadır. Fakat, kırılma sonrası her iki test de eşbütünleşme ilişkisini reddetmektedir. İlişkinin olduğu modellerde katsayıların beklenen işaretleri ise, reel döviz kurunda beklentiler doğrultusundayken faiz haddi oranında ise beklenti tersidir.

Eşbütünleşme analiz sonucunda, "Alış-Veriş Maliyetleri Parasal Hizmet Modelinin” Türkiye uygulamasında, güçlü bazı eğilimler ortaya çıkmaktadır.

15 Eşbütünleşme analiz sonuçları çok daha detaylı olarak yapılacağından burada sınırlandırılmıştır. Burada sadece ilişkinin varlığı ve beklenen işaretler üzerinde durulmuştur.

${ }^{16}$ Trace test, Türkçe'ye iz testi olarak çevrilmiştir. Bkz. Şıklar (2000) ve Üçdoğruk (1996). 
$\mathrm{Bu}$ eğilimlerin başında, reel döviz kuru belirsizliğinin para ikamesinin açıklanmasında güçlü bir değişken olduğudur. Kırılmalarla farklı dönemlere bölünen ve eşbütünleşme ilişkisi bulunan dönemlerde reel döviz kuru katsayısı hep beklentiler doğrultusunda çıkmıştır. Faiz haddi ise beklentilerin tersi işareti vermiştir. Türkiye verileriyle modelin uygulama sonuçları alınmadan önce sezgisel olarak reel döviz kurunun anlamlı çıkacağı beklenmekle birlikte, faiz haddi oranına şüphe ile yaklaşılmaktaydı.

Faiz değişkeninin beklenen pozitif işareti vermemesinin potansiyel nedenleri birkaç faktörden oluşabilir. Bunlardan biricisi, sermaye hareketleridir. Türk hazine bonosu faiz oranlarını yükselttiğinde, yerleşikler dövizden Türk hazine bonosuna yönelmektedirler. $\mathrm{Bu}$ yönelme, dövizde talebi azaltmakta, hazine bonosuna olan talep artırmaktadır. Benzer şekilde, uluslararası yatırımcılar da, ülkeye sıcak para olarak sermaye girişi ile hazine bonosuna yönelmektedirler. Fakat, sermaye girişinin yaşanması ülkedeki döviz balanslarını yükseltmektedir. Başka bir ifadeyle, hazine bonosunun faiz oranlarını yükseltmesi, sermaye girişinden dolayı döviz balanslarını azaltmak yerine artırıcı etki yapmaktadır. Faiz değişkeninin ters işaretli çıkmasının ikinci faktörü, Türkiye'nin aşırı borçlu ülke olmasından dolayı taşıdığı ülke riski olabilir. Türkiye, dünya finans merkezleri tarafından riskli ülke olarak değerlendirildiği dönemlerde, hazine faiz oranı ne kadar yüksek verilirse verilsin, borçlanma gerçekleştirilememektedir. Bu durum, Türkiye'nin zaman zaman IMF ile stand-by anlaşmaları yaparak, uluslararası piyasalarda borçlanmaya yönelmesi ile daha açık bir şekilde görülebilmektedir. Belirtilen bu iki faktör, para ikamesinin faiz hadlerine duyarsız bazen de tersi yönde hareket etmesine neden olabilir. Fakat, bu faktörlerin para ikamesi üzerindeki etkileri ölçülmediğinden bu tespit sezgisel nitelikten öteye geçememektedir. 
A. Çetin / Sosyal Bilimler Araştırmaları Dergisi , 1, (2006): 15-39

Tablo 6. M2 Kullanılan Eşbütünleşme Analizi Sonuçları

\begin{tabular}{|c|c|c|c|}
\hline \multicolumn{4}{|c|}{ TAM DÖNEM (1989:01 - 1999:12) } \\
\hline & $\mathrm{r}=0$ & $\mathrm{r} \leq 1$ & $\mathrm{r} \leq 2$ \\
\hline $\mathrm{LR}_{\mathrm{iz}}$ & $24.35^{*}$ & 8.82 & 0.01 \\
\hline $\mathrm{LR}_{\max }$ & 16.10 & 8.80 & 0.0001 \\
\hline \multirow{2}{*}{$\begin{array}{l}\text { Eşbütünleşme } \\
\text { Denklemi }\end{array}$} & $\log (\mathrm{M} 2 / \mathrm{DTH})$ & $\log \left[\left(r_{f} / r_{d}\right)(1+\varepsilon)\right]$ & $\log \left[\mathrm{S} .\left(\mathrm{P}_{\mathrm{f}} / \mathrm{P}_{\mathrm{d}}\right)\right]$ \\
\hline & 1.00 & $\begin{array}{l}-1.210150 \\
(-10.2550)\end{array}$ & $\begin{array}{l}-0.600035 \\
(-11.5447)\end{array}$ \\
\hline \multicolumn{4}{|c|}{ Kullanılan gecikme uzunluğu $^{(\mathrm{a})}=2$} \\
\hline \multicolumn{4}{|c|}{ YAPISAL KIRILMA ÖNCESİ (1989:01 - 1993:02) } \\
\hline & $\mathrm{r}=0$ & $\mathrm{r} \leq 1$ & $r \leq 2$ \\
\hline $\mathrm{LR}_{\mathrm{iz}}$ & $25.39^{*}$ & 4.55 & 0.00004 \\
\hline $\mathrm{LR}_{\max }$ & $20.84 *$ & 4.55 & 0.00004 \\
\hline \multirow{2}{*}{$\begin{array}{l}\text { Eşbütünleşme } \\
\text { Denklemi }\end{array}$} & $\log (\mathrm{M} 2 / \mathrm{DTH})$ & $\log \left[\left(\mathrm{r}_{\mathrm{f}} / \mathrm{r}_{\mathrm{d}}\right)(1+\varepsilon)\right]$ & $\log \left[\mathrm{S} .\left(\mathrm{P}_{\mathrm{f}} / \mathrm{P}_{\mathrm{d}}\right)\right]$ \\
\hline & 1.00 & $\begin{array}{l}-1.028460 \\
(-12.3761)\end{array}$ & $\begin{array}{l}-0.527252 \\
(-17.8487)\end{array}$ \\
\hline \multicolumn{4}{|c|}{ Kullanılan gecikme uzunluğu $^{(\mathrm{b})}=1$} \\
\hline \multicolumn{4}{|c|}{ YAPISAL KIRILMA SONRASI (1993:03 - 1999:12) } \\
\hline & $\mathrm{r}=0$ & $\mathrm{r} \leq 1$ & $\mathrm{r} \leq 2$ \\
\hline $\mathrm{LR}_{\mathrm{iz}}$ & 22.87 & 7.69 & 0.0008 \\
\hline $\mathrm{LR}_{\max }$ & 15.18 & 7.69 & 0.0008 \\
\hline \multirow{2}{*}{$\begin{array}{l}\text { Eşbütünleşme } \\
\text { Denklemi }\end{array}$} & $\log (\mathrm{M} 2 / \mathrm{DTH})$ & $\log \left[\left(r_{f} / r_{d}\right)(1+\varepsilon)\right]$ & $\log \left[\mathrm{S} .\left(\mathrm{P}_{\mathrm{f}} / \mathrm{P}_{\mathrm{d}}\right)\right]$ \\
\hline & ---- & ---- & --- \\
\hline \multicolumn{4}{|c|}{ Kullanılan gecikme uzunluğ $^{(a)}=2$} \\
\hline $\begin{array}{l}\text { Not: }{ }^{*} \text { ve }{ }^{* *}, \\
\text { göstermektedir. Par } \\
\text { FPE:Final tahmin } \\
\text { Quinn bilgi ölçütü } \\
\text { (a) En uygun gecikn } \\
\text { (b) Fn }\end{array}$ & $\begin{array}{l}\text { rasıyla, } \% 5 \text { ve } \% \\
\text { ntez içindeki değerler } \\
\text { tası, AIC: Akaike bi }\end{array}$ & $\begin{array}{l}\text { önem düzeyinde eş } \\
\text { test değerlerini ifade } \\
\text { i ölçütü, SC: Schwa }\end{array}$ & $\begin{array}{l}\text { leşme ilişkisi olduğ } \\
\text { stedirler. } \\
\text { si ölçütü, HQ: Hann }\end{array}$ \\
\hline
\end{tabular}


A. Çetin / Sosyal Bilimler Araştırmaları Dergisi , 1, (2006): 15-39

\section{Sonuç ve Öneriler}

Bu çalışmada Ratti ve Jeong (1994)'un yapmış oldukları parasal hizmet modelinin alış-veriş maliyetleri modeli Türkiye verileri 1989:01-1999:12 dönemlerine uygulanmıştır. Model uygulanırken, Türkiye verilerine uyumlu hale getirilmek için bazı düzenlemeler yapılmıştır. Orijinal modelde döviz kuru beklenen değişim oranı, vadeli döviz kuru ile spot döviz kuru arasındaki fark olarak temsil edilmiştir. Türkiye'de vadeli döviz kuru piyasası olmadığından, döviz kuru beklenen değişim oranı, döviz kurundaki değişkenlik GARCH modeliyle tahmin edilerek temsil edilmiş̧ir. Ayrıca Türkiye'deki para ikamesi, inceleme döneminde büyük ölçüde dolar ve mark olarak gerçekleşmiştir. Bu nedenle, bu iki yabancı paradan oluşan efektif döviz kuru kullanılmıştır. Yapılan ön çalışmalarda 0.75 dolar artı 0.25 mark oranında yapılan ağırlıklandırmanın en uygun efektif döviz kuru olduğu tespit edilmiştir.

Elde edilen sonuçların, Alış-Veriş Maliyetleri Parasal Hizmet Modeli'ni uygulayan diğer çalışma sonuçları ile mukayese edilmesi, bu çalışmada elde edilen sonuçların değerlendirmesine 1şık tutabilir. Alış-Veriş Maliyetleri Parasal Hizmet Modeli, bu çalışma dışında iki ayrı çalışmada uygulanmıştır. Bunlardan birincisi modeli geliştiren Ratti ve Jeong (1994)'un ABD ile Kanada arasında yapmış oldukları çalışmadır. Diğeri ise Milner, Mizen ve Pentecost (1996)'un Avrupa'da yedi ülkenin Sterlin ile ikamesini inceleyen çalışmadır.

Ratti ve Jeong (1994)'un çalışmalarında, yerel ülke olarak Kanada ve yabancı ülke olarak ABD alınmıştır. Ulaşılan sonuçlar ile modelin beklentileri tam bir uyum içindedir. Tüm değişkenler anlamlı ve beklenen işaretler doğrultusunda çıkmıştır. Sonuçların bu düzeyde uyumlu olması, bu iki ülkenin çok istikrarlı makroekonomik değişkenlere sahip olması ile açıklanabilir.

Ancak modelin Avrupa versiyonu, Kuzey Amerika uygulaması gibi beklenen sonuçlar vermemiştir. Milner ve diğerleri (1996) yapmış oldukları çalışmada yedi Avrupa ülkesinde (Belçika, Almanya, İrlanda, İtalya, Hollanda, Danimarka ve Fransa), para ikamesini incelerken her ülkenin ulusal parası ile İngiliz sterlini arasındaki ikame incelenmiştir. Çalışmada çıkan sonuçlar, Kuzey Amerika versiyonundan oldukça farklılık göstermektedir. Yedi ülkenin beşinde eşbütünleşme ilişkisi tespit edilebilmiş, Danimarka ve Fransa verilerinde eşbütünleşme ilişkisi bulunamamıştır. Almanya'nın dış ticaret değişkeni 
durağan çıktığından bu değişken eşbütünleşme modeline alınmamıştır. ${ }^{17}$ Ulaşılan güzel sonuçlardan biri, dış ticaret değişkeni her ülkede beklentiler doğrultusunda çıkmıştır. Buna rağmen reel döviz kuru değişkeninin işareti sadece İrlanda ve İtalya'da beklentiler doğrultusunda çıkmıştır. Göreceli faiz oranı ise sadece İrlanda da beklenen işaretin tersini vermiştir. Modelle tam uyum içinde olan tek ülke İtalya çıkmıştır. İtalya'da tüm değişkenler beklentiler doğrultusunda ve anlamlı çıkmıştır.

Modelin Türkiye uygulaması niteliğinde olan bu çalışmada ise Avrupa uygulamasına benzer sonuçlar elde edilmiştir. Model, her ne kadar para ikamesinde ülkeler arasındaki faiz farklılıklarını, reel döviz kuru ve dış ticaret faktörlerini kaynak olarak gösteriyorsa da, Türkiye uygulamasında reel döviz kuru en önemli faktör olarak beklenmekteydi. Türkiye'de, ülkeler arası faiz farklılıklarının neden ters işaretli çıktığının cevabı, Türkiye'nin dış borç yükünün yüksek olması ve zaman zaman finansal krizlerin yaşanması, bu değişkeni büyük ölçüde etkilemektedir. Krizler öncesi ve sonrasında hazinenin ulusal ve uluslararası finansal piyasalarda borçlanamaması, dini motivasyonla toplumun bir kısmının faiz değişmelerine karşı duyarsız kalması ve sıcak paranın ters yönde etki yapması ülkeler arası faiz oranı farklılı̆̆ının neden beklendiği gibi çıkmadığının ipuçlarını vermektedir.

Türkiye uygulamasında, beklentiler reel döviz kurunun anlamlı ve etkili ç1kması yönündeydi. Reel döviz kuru tüm dönemlerde \% 1 önem seviyesinde beklenen işaretleri vermiştir. Veri setinde yapısal kırılmalar olmasına rağmen, yapısal kırılmaları dikkate almayan tam modellerde bile reel döviz kurunun \% 1 önem seviyesinde beklenen işareti vermesi, bu değişkenin etkinliği hakkında fikir vermektedir. Dış ticaret değişkeni ise, inceleme döneminde durağan çıktığından eşbütünleşme analizine dahil edilememiştir.

Sonuç olarak Türkiye'de para ikamesinin reel döviz kuru belirsizliğinden kaynaklandığı yönünde önemli bulgular elde edilmiştir.

\footnotetext{
${ }^{17}$ Türkiye uygulamasında da dış ticaret değişkeni durağan çıkmış ve eşbütünleşme modeline dahil edilmemiştir.
} 


\section{Kaynaklar}

Andrews, D. W. (1993) "The Test for Parameter Instability and Structural Change with Unknown Change Point." Econometrica, 61, 4: 821-856.

Ben-David, D. ve D. H. Papell (1994). "The Great Wars, the Great Crash, and the Unit Root Hypothesis: Some New Evidence about an Old Stylized Fact." National Bureau of Economic Research, WP No. 4752.

Bergstrant, J. H. ve T. P. Bundt (1990). Currency Substitution and Monetary Autonomy: the Foreign Demand for US Demand Deposits. Journal of International Money and Finance 9 (3):325-334.

Branson, W. H. ve D. W. Henderson (1985) The Specification and Influence of Asset Markets. In R. W. Jones and P. B. Kenen (eds), Handbook of International Economics, Vol. II. Amsterdam: North Holland.

Calvo, G. A. ve C. A. Rodriguez (1977). "A Model of Exchange Rate Determination under Currency Substitution and Rational Expectations." Journal of Political Economy, 85, 31: 617-625.

Calvo G. A. ve C. A. Vegh (1992). "Currency Substitution in Developing Countries: An Introduction." IMF Working Paper, 40.

Chow, G. C. (1960). "Tests Of Equality Between Sets Of Coefficients In Two Linear Regressions." Econometrica, 28, 591-605.

Cuddington, J. T. (1989). "Currency Substitution: Theory and Evidence for Latin America by Victor A. Canto and Genald Nickelsburg: Book Review" Journal of Money, Credit and Banking, 21, 267-271.

Dickey, D., ve W. A. Fuller (1979). "Distribution of the Estimates for Autoregressive Time Series with a Unit Root" Journal of the American Statistical Association, 74: 427-31.

Dickey, D., ve W. A. Fuller (1981). "Likelihood Ratio Statistics for Autoregressive Time Series with a Unit Root." Econometrica, 49, 105772.

Enders, W. (1995). Applied Econometric Time Series, New York, USA, John Wiley \& Sons

Engel, R., ve C. W. Granger (1987). "Cointegration and Error Correction: Representation, Estimation and Testing." Econometrica, 55, 251-277.

Gregory, A. W. ve B. E. Hansen (1996). "Residual-Based Test for Cointegration in Models with Regime Shifts." Journal of Econometrics, $70,99-126$

Handa, J. ve I. M. Bana (1999). "Currency Substitution and Transactions Costs" Empirical Economics, 15: 231-243. 
Johanson, S. ve K. Juselius (1990). "Maximum Likelihood Estimation and Inferences on Cointegration with Application to the Demand for Money" Oxford Bulletin of Economics and Statistics, 52, 169-210.

Joines, D. H. (1985) "International Currency Substitution And Income Velocity Of Money" Journal Of International Money And Finance, 4, 303-316.

Kouri, P. (1976) "The Exchange Rates And The Balance Of Payments In The Short Run And The Long Run: A Monetary Approach." Scandinavian Journal Of Economics, 78, 280-304.

McKinnon, R. I. (1985) "Two Concepts of International Currency Substitution." The Economics of Carribean Basin Connolly, M. D. ve J. McDermont (Ed), New York: Praeger.

Miles, M. (1978). "Currency Substitution, Flexible Exchange Rate, Monetary Independence." American Economic Review, 68, 3, 428-436.

Milner, C., P. Mizen ve E. Pentecost (1996). "The Impact Of Intra-European Trade On Sterling Currency Substitution." Weltwirtschaftliches ArchivReview of World Economics, 132, 1, 160-171.

Phillips, P. ve P. Perron (1988). "Testing for a Unit Root in Time Series Regression." Biometrica, 75, 335-46.

RATTI, R. A. ve B. W. JEONG (1994). "Variation in the Real Exchange Rate as a Source of Currency Substitution." Journal of International Money and Finance, 13, 5, 537-550.

Rogers, J. H (1990). "Foreign Inflation Transmission under Flexible Exchange Rate and Currency Substitution." Journal of Money, Credit, and Banking, 22, 2, 195-208.

Şiklar, E. (2000). “Eşbütünleşme Analizi ve Türkiye'de Para Talebi.” Eskişehir: Anadolu Üniveritesi Yayınları No.1206.

Telatar, E. (1996). "Kısa Dönem Döviz Kuru Belirsizliğinin Ölçülmesi: GARCH Modeli." Hazine Dergisi, 2, Nisan, 103-115.

Telatar, F. (2003). "Türkiye'de Enflasyon, Enflasyon Belirsizliği ve Siyasi Belirsizlik Arasındaki Nedensellik İlişkileri“. İktisat İşletme ve Finans, Şubat, 42-51.

Thomas, L. R. (1985). "Portfolio Theory and Currency Substitution." Journal of Money, Credit and Banking, 17, 3, 347-357.

Üçdoğruk, Ş. (1996). "Türkiye Para Talebi Modeli: Eşbütünleşme Analiz İlişkileri." Iktisat İşletme ve Finans, 126, 30-40. 
Zervoyianni, A. (1988). "Exchange Rate Overshooting, Currency Substitution and Monetary Policy." The Manchester School of Economics \& Social Studies, 56, 3, 247-67.

Zervoyianni, A. (1992). International Macroeconomic Interdependence, Currency Substitution, and Price Stickiness. Journal of Macroeconomics 15 (1):59-86.

Zivot, E. ve Donald A. (1992). "Further Evidence on the Great Crash, the Oil Price Shock, and the Unit Root Hypothesis." Journal of Business and Economics, 10, 251-270.

\section{EK 1: Kullanılan Serilerin Özellikleri}

M2 :TCMB, Elektronik Veri Dağıtım Sistemi (EVDS)'den alınmıştır. Milyar TL olarak ölçülmektedir. Yerli para arzını temsil etmek için kullanılmışlardır. Modelde $\mathrm{M}_{\mathrm{d}}$ değiş̧keninin temsil etmektedir.

DTH :TCMB, EVDS'den alınmıştır. Milyar TL olarak ölçülmektedir. Türk bankacılık sistemi içindeki gerçek ve tüzel kişilere ait yabancı paraların TL toplamını ifade etmektedir. Modelde $\mathrm{M}_{\mathrm{f}}$ değişkeninin temsil etmektedir.

S :Efektif (Spot) döviz kurunu ifade etmektedir. 0.75 ABD dolar kuru ile 0.25 Alman mark kuru ağırlığıyla oluşturulmuştur. ABD dolar ve Alman mark kurları TCMB EVDS' de döviz alış değerleriyle alınmıştır.

$\mathrm{r}_{\mathrm{f}} \quad$ :Yabanc1 ülke (ABD ve Almanya) bono faiz oranını temsil etmektedir. Efektif döviz kuruna uyumlu olarak 0.75 ABD hazine bono faiz oranı ve 0.25 Almanya hazine bono faiz oranı ağırlığından oluşturulmuştur. ABD ve Alman hazine bono faiz oranları sirasiyla IFS $11160 \mathrm{C}$, , ZF, , ve 13460 $\mathrm{C}, \mathrm{ZF}$,, serilerinden alınmıştır.

$\mathrm{r}_{\mathrm{d}} \quad$ :Yerli ülke (Türkiye) hazine bonosu faiz oranının temsil etmektedir. IFS 18660C,ZZF,, serisinden alınmıştır. Seride eksik olan veriler IFS hesaplamasına uygun olarak hesaplamıştır. Fakat Türk hazine bono ihalesi yapılmadığ 1997:04, 1997:05 ve 1999:12 dönemlerin ait veri elde etmek için SAS programının tahmin metotları kullanılarak veri elde edilmiştir.

$\varepsilon \quad$ :Döviz kurunda beklenen değişim oranını temsil etmektedir. Efektif döviz kuru serisindeki değişkenlik GARCH modeli ile tahmin edilerek $\varepsilon$ serisi oluşturulmuştur. 
$\mathrm{P}_{\mathrm{f}} \quad$ :Yabanci ülke (ABD ve Almanya) fiyat endeksini (tüketici fiyat endeksi) temsil etmektedir. Efektif döviz kuruna uyumlu olarak 0.75 ABD tüketici fiyat endeksi ve 0.25 Almanya tüketici fiyat endeksi ağırlığından oluşturulmuştur. ABD ve Alman tüketici fiyat endeksleri sırasıyla IFS 11164,, ZF,, ve 13464,,, ZF,,, serilerinden alınmıştır. Seriler 1987:01=100 olarak normalleştirilmiştir.

$\mathrm{P}_{\mathrm{d}} \quad$ :Yerel ülke (Türkiye) Tüketici Fiyat Endeksini (TÜFE) temsil etmektedir. TCMB, EVDS'de alınmıştır. 1987:01=100 olarak normalleştirilmiştir.

E :Yerli ülke (Türkiye) toplam ihracatının temsil etmektedir. TCMB, EVDS'den alınmıştır. Milyar TL olarak ölçülmüştür.

M :Yerli ülke (Türkiye) toplam ithalatının temsil etmektedir. TCMB, EVDS'den alınmıştır. Milyar TL olarak ölçülmüştür. 